03

\title{
Теневая визуализация турбулентного обмена между вихревым кольцом и окружающей средой при различных плотностях жидкостей в вихре и вне его
}

\author{
(C) В.В. Никулин \\ Институт гидродинамики им. М.А. Лаврентьева СО РАН, Новосибирск, Россия \\ E-mail: nikulin@hydro.nsc.ru
}

Поступило в Редакцию 20 апреля 2018г.

В окончательной редакции 28 декабря 2018 г.

Принято к публикации 28 декабря 2018 г.

Выполнено экспериментальное наблюдение турбулентного обмена между вихревым кольцом и окружающей средой с помощью теневой визуализации процесса, когда плотности жидкости в вихре и вне его различны. Определен проходимый вихрем характерный путь турбулентного обмена, найдена зависимость пути от скорости вихря и связанного с ней числа Рейнольдса.

DOI: 10.21883/PJTF.2019.07.47527.17350

Исследование турбулентного обмена между вихревым кольцом и окружающей средой представляет фундаментальный и практический интерес. Фундаментальное значение состоит в том, что вихревое кольцо является примером изолированного концентрированного вихря, поэтому закономерности, установленные при его исследовании, связаны с вихревым характером течения и могут быть перенесены на другие концентрированные вихри, в частности линейные. Практическое значение обусловлено тем, что вихревые кольца нередко возникают в различных техногенных и природных процессах (например, при взрывах, извержении вулканов). Перенос мелкодисперсного порошка вихревыми кольцами нашел применение в вихрепорошковом методе тушения пожаров на аварийно фонтанирующих газовых и нефтяных скважинах [1]. Для создания плазменных излучателей оптического диапазона предложено генерировать течение плазмы таким образом, чтобы возникали вихревые кольца [2]. В указанных случаях необходимо уметь оценивать характеристики турбулентного обмена, поскольку в результате его происходит унос примесей и тепла из вихря. Кроме того, динамика вихревых колец, в частности их коэффициент расширения, тесно связаны с затуханием вращения за счет диссипативных процессов, обусловленных турбулентностью $[3,4]$.

Известно, что вихревое кольцо представляет собой тороидальный объем завихренной жидкости или газа (ядро вихря), вместе с которым движется некоторый окружающий объем среды, называемый атмосферой вихря. Исследование турбулентности в таких образованиях существенно осложняется нестационарным и вихревым характером течения, поэтому нахождение каких-либо турбулентных характеристик является важным достижением. К настоящему времени экспериментально установлено, что обмен между вихрем и окружающей средой в основном идет из его атмосферы, в то время как турбулентность в ядре подавлена [5]. Однако количественных характеристик данных процессов не получено. В работе [6] дано теоретическое обоснование подавления турбулентности в твердотельно вращающейся жидкости. Потери пассивной примеси вихревым кольцом, обусловленные турбулентностью, экспериментально исследованы в [7]. Получена эмпирическая зависимость доли переносимой примеси от пройденного вихревым кольцом пути. Однако характерное расстояние, на котором осуществляется турбулентный обмен, и его зависимость от параметров движения не установлены. В связи с этим на основе представленных данных делать количественные выводы о характеристиках турбулентного обмена, а также о их зависимости от параметров вихря не представляется возможным.

В настоящей работе для наблюдения турбулентного обмена между вихревым кольцом и окружающей средой используется теневая визуализация. Для этого создаются вихревые кольца, плотность жидкости в которых выше, чем в окружающей среде. Эксперименты выполнены при различных разностях плотностей и скоростях движения вихря. Предложена методика обработки теневых изображений. По результатам обработки определяется расстояние, проходимое вихрем, которое характеризует процесс турбулентного обмена, находится зависимость этого расстояния от скорости вихря и связанного с ней числа Рейнольдса.

Экспериментальная установка представляет собой вертикальный сосуд высотой $300 \mathrm{~mm}$, сечением $150 \times 150 \mathrm{~mm}$, заполненный двухслойной жидкостью: верхний слой - вода плотностью $\rho_{1}=1 \mathrm{~g} / \mathrm{cm}^{3}-$ глубиной $180 \mathrm{~mm}$, нижний - раствор сахара различной плотности $\left(\rho_{2}=1.08,1.04,1.02 \mathrm{~g} / \mathrm{cm}^{3}\right)$ — глубиной $70 \mathrm{~mm}$. Вихревые кольца образуются в нижнем слое путем выталкивания импульсной струи длиной $34 \mathrm{~mm}$ из цилиндрической камеры диаметром $21 \mathrm{~mm}$ через сопло диаметром $12.5 \mathrm{~mm}$. Расстояние от среза сопла до границы раздела $40 \mathrm{~mm}$. Вихрь формируется в нижнем слое и 

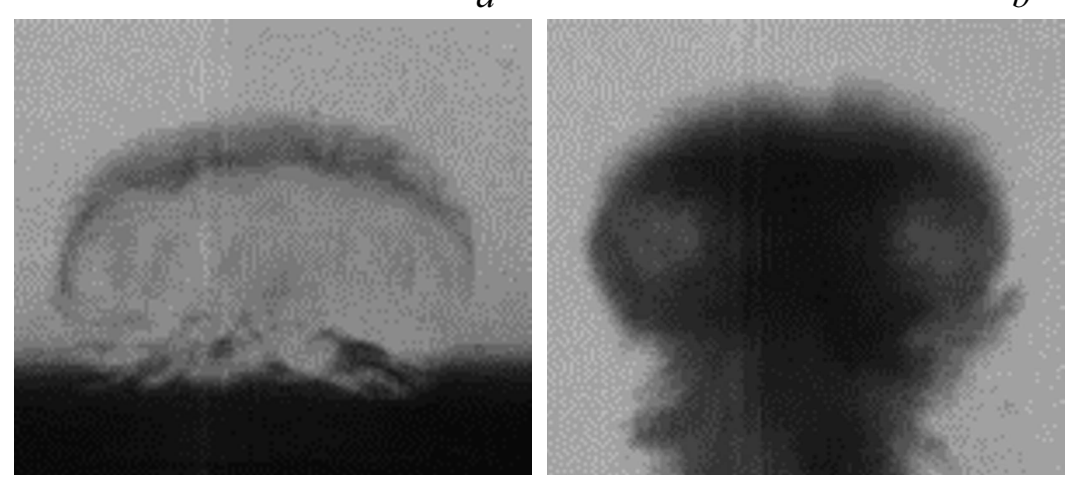

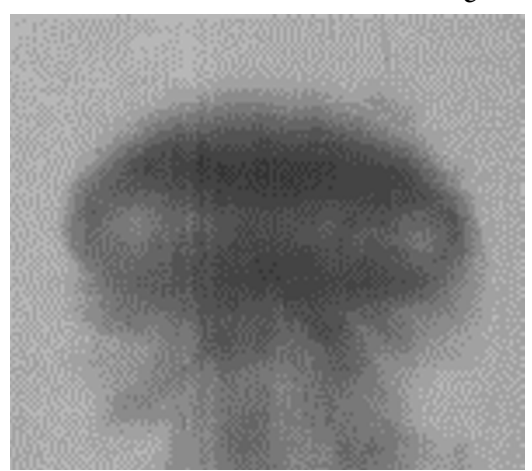

Рис. 1. Теневые фотографии вихревого кольца на различных расстояниях от границы раздела: $5(a), 30(b)$ и $83 \mathrm{~mm}(c)$. Плотность нижнего слоя $\rho_{2}=1.08 \mathrm{~g} / \mathrm{cm}^{3}$, скорость вихря $u=2.9 \mathrm{~m} / \mathrm{s}, \operatorname{Re}=21750$.

выходит в верхний, оставаясь заполненным жидкостью более плотной, чем окружающая. Движение вихревого кольца регистрируется скоростной видеокамерой. Производится теневая съемка на просвет перпендикулярно направлению движения с частотой от 125 до 1000 кадров в секунду. В качестве параметров вихря принимаются его скорость $u$ и радиус осевой линии тороидального ядра $R$ в момент, когда вихрь находится на расстоянии 15-20 mm от границы раздела. По этим значениям и кинематической вязкости воды, принятой равной $10^{-2} \mathrm{~cm}^{2} / \mathrm{s}$, рассчитывается число Рейнольдса.

На рис. 1 показаны теневые изображения вихревого кольца в верхнем слое на различных расстояниях от границы раздела. Сразу после выхода вихря из нижнего слоя визуализируется граница его атмосферы, поскольку внутри вихря и вне его жидкости однородны (рис. 1,a). По мере движения однородность сред нарушается, в них попадают турбулентные объемы другой жидкости, в результате чего возникают градиенты плотности и происходит теневая визуализация. Для вихревого кольца это выглядит как резкое потемнение атмосферы. Сначала потемнение увеличивается (рис. $1, b$ ), затем начиная с некоторого расстояния уменьшается (рис. 1, c) практически до полного просветления. Это означает, что количество более плотной жидкости в вихре убывает, происходит ее замена окружающей. На теневых изображениях можно видеть ядро вихря, которое из-за эффекта подавления турбулентности более светлое, чем его окружение. По изображениям определяется диаметр осевой линии тора, форму которого имеет ядро. За расстояние $z$ от границы раздела до вихревого кольца принимается расстояние от границы до осевой линии, поскольку ядро параллельно границе. В качестве скорости принимается среднее значение при перемещении вихря на 10-20 mm.

Для получения количественной характеристики величины потемнения предложена следующая методика обработки каждого эксперимента. Согласно рис. 1, $a$, вихрь вместе с атмосферой хорошо виден сразу после выхода из нижнего слоя. По этому изображению создается шаблон формы его атмосферы. Движение регистрируется на пути длиной до шести диаметров кольца. Известно, что на таком протяжении параметры вихря изменяются незначительно [1], что наблюдается и в наших экспериментах. Поэтому полагается, что размеры атмосферы вихревого кольца на пути наблюдения не изменяются, хотя из-за потери более плотной жидкости внешняя часть атмосферы может быть не видна (рис. 1,c). Шаблон накладывается на фотографии, регистрирующие положение вихря на различных расстояниях от границы, при этом он позиционируется одинаковым образом относительно ядра вихря. Затем определяется интегральное почернение внутри площади шаблона, по нему вычисляется среднее почернение на один пиксель в процентах от максимально возможного. В экспериментах варьируется начальная скорость от 0.4 до $4.2 \mathrm{~m} / \mathrm{s}$, что соответствует изменению чисел Рейнольдса от 3000 до 31500 . Диаметр кольца примерно одинаков и равен $15 \pm 0.5 \mathrm{~mm}$. На рис. 2 показано среднее почернение $J$ (в процентах) в зависимости от расстояния до границы раздела для случая $\rho_{2}=1.08 \mathrm{~g} / \mathrm{cm}^{3}$, $u=2.9 \mathrm{~m} / \mathrm{s}, \operatorname{Re}=21750$. Точки - экспериментальные значения, сплошная кривая - $b$-сплайн интерполяция точек. Виден ярко выраженный максимум почернения. Подобная зависимость является типичной, максимум наблюдается при всех скоростях вихря и плотностях нижнего слоя. При изменении скорости и плотности изменяется величина почернения: чем больше скорость и плотность, тем больше почернение.

Поскольку почернение связано с турбулентным обменом, расстояние, проходимое вихрем от границы раздела до места, где оно максимально, очевидно, является характерным для данного процесса. Можно предположить, что в этом месте происходит максимальное перемешивание, т. е. примерно половина первоначальной жидкости, заполнявшей вихрь, заменяется окружающей. В связи с этим расстояние от границы раздела до положения вихря, где наблюдается его максимальное почернение, принимается в качестве характерного для процесса турбулентного обмена между вихревым кольцом и окружающей жидкостью. Данное расстояние надежно 


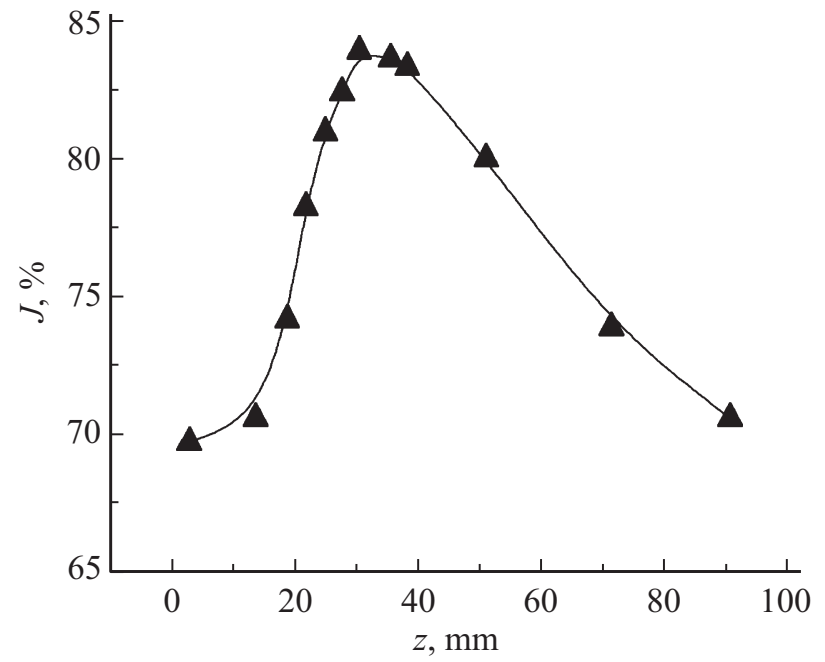

Рис. 2. Зависимость среднего почернения вихревого кольца от расстояния до границы раздела. Плотность нижнего слоя $\rho_{2}=1.08 \mathrm{~g} / \mathrm{cm}^{3}$, скорость вихря $u=2.9 \mathrm{~m} / \mathrm{s}, \mathrm{Re}=21750$.

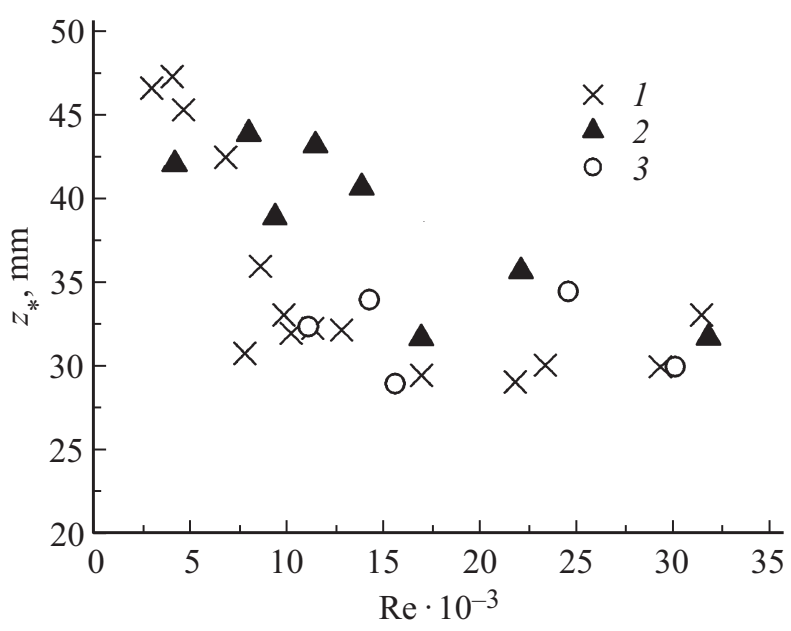

Рис. 3. Расстояние $z_{*}$ от границы раздела до вихревого кольца, где наблюдается его максимальное среднее почернение, в зависимости от числа Рейнольдса вихря при различных плотностях нижнего слоя: $\rho_{2}=1.08$ (1), 1.04 (2) и $1.02 \mathrm{~g} / \mathrm{cm}^{3}$ (3).

определяется в каждом эксперименте и обозначается через $z_{*}$.

На рис. 3 показана зависимость $z_{*}$ от числа $\mathrm{Re}$ вихря при различных плотностях нижнего слоя. Точки соответствуют $\rho_{2}=1.08(1), 1.04$ (2) и $1.02 \mathrm{~g} / \mathrm{cm}^{3}$ (3). При $\rho_{2}=1.02 \mathrm{~g} / \mathrm{cm}^{3}$ из-за малой разницы плотностей жидкостей в вихре и вне его теневое изображение видно лишь при достаточно больших числах $\operatorname{Re}>10^{4}$. Из рис. 3 следует, что при небольших скоростях величина $z_{*}$ убывает с увеличением скорости вихря и плотности нижнего слоя, а при больших скоростях практически перестает от них зависеть. По данным для всех плотностей и $\operatorname{Re}>10^{4}$, представленным на рис. 3 , вычислены среднее значение величины $z_{*}$ и ее дисперсия. Оказалось, что $z_{*}=32.7 \pm 3.8 \mathrm{~mm}$, что примерно равно двум диаметрам вихревого кольца. Поскольку при $\operatorname{Re}>10^{4}$ величина $z_{*}$ практически не зависит от разницы плотностей, в этой области она характеризует турбулентный обмен и в однородной жидкости.

Таким образом, выполнено экспериментальное наблюдение турбулентного обмена между вихревым кольцом и окружающей средой путем теневой визуализации процесса, когда плотности жидкости в вихре и вне его различны. Установлено, что существует характерное расстояние, проходимое вихрем, на котором потемнение изображения достигает максимума. Определена зависимость расстояния от скорости вихря и связанного с ней числа Рейнольдса. Установлено, что при $\mathrm{Re}>10^{4}$ характерное расстояние практически не зависит от Re. Поскольку потемнение изображения вызвано турбулентным обменом, найденное расстояние является характерным для процесса турбулентного обмена.

Работа поддержана РФФИ (грант № 18-08-00824).

\section{Список литературы}

[1] Ахметов Д.Г. Вихревые кольца. Новосибирск: ГЕО, 2007. $152 \mathrm{c}$.

[2] Буланов С.С., Есиев Р.У., Камруков А.С., Козлов Н.П., Морозов М.И., Росляков И.А. // ЖТФ. 2010. Т. 80. В. 11. C. 87-94.

[3] Никулин В.В. // ПМТФ. 2014. № 4. С. 11-18.

[4] Никулин В.В. // Изв. РАН. Механика жидкости и газа. 2017. № 1. С. 90-95.

[5] Владимиров В.А., Тарасов В.Ф. // ДАН СССР. 1979. Т. 245. № 6. C. 329-333.

[6] Nikulin V., Savtchenko S., Ashgriz N. // Phys. Lett. A. 2017. V. 381. P. 3989-3995.

[7] Тарасов В.Ф., Якушев В.И. // ПМТФ. 1974. № 1. С. 130-136. 